Research article

Open Access

\title{
Alphavirus replicon particles containing the gene for HER2/neu inhibit breast cancer growth and tumorigenesis
}

\author{
Xiaoyan Wang ${ }^{1,2}$, Jian-Ping Wang ${ }^{1}$, Maureen F Maughan ${ }^{3}$ and Lawrence B Lachman ${ }^{1,2}$
}

\author{
${ }^{1}$ Department of Bioimmunotherapy, The University of Texas MD Anderson Cancer Center, Houston, Texas, USA \\ 2The Graduate School of Biomedical Sciences, The University of Texas Health Sciences Center, Houston, Texas, USA \\ ${ }^{3}$ AlphaVax, Inc., Research Triangle Park, North Carolina, USA \\ Corresponding author: Lawrence B Lachman, Lachman@odin.mdacc.tmc.edu
}

Received: 1 Jul 2004 Revisions requested: 8 Sep 2004 Revisions received: 9 Sep 2004 Accepted: 13 Oct 2004 Published: 29 Nov 2004

Breast Cancer Res 2005, 7:R145-R155 (DOI 10.1186/bcr962)

(C) 2004 Wang et al., licensee BioMed Central Ltd.

This is an Open Access article distributed under the terms of the Creative Commons Attribution License (http://creativecommons.org/licenses/by/ 2.0), which permits unrestricted use, distribution, and reproduction in any medium, provided the original work is cited.

\begin{abstract}
Introduction Overexpression of the HER2/neu gene in breast cancer is associated with an increased incidence of metastatic disease and with a poor prognosis. Although passive immunotherapy with the humanized monoclonal antibody trastuzumab (Herceptin) has shown some effect, a vaccine capable of inducing T-cell and humoral immunity could be more effective.

Methods Virus-like replicon particles (VRP) of Venezuelan equine encephalitis virus containing the gene for HER2/neu (VRP-neu) were tested by an active immunotherapeutic approach in tumor prevention models and in a metastasis prevention model.
\end{abstract}

Results VRP-neu prevented or significantly inhibited the growth of HER2/neu-expressing murine breast cancer cells injected either into mammary tissue or intravenously. Vaccination with VRP-neu completely prevented tumor formation in and death of MMTV-c-neu transgenic mice, and resulted in high levels of neuspecific CD8+ $\mathrm{T}$ lymphocytes and serum IgG.

Conclusion On the basis of these findings, clinical testing of this vaccine in patients with HER2/neu+ breast cancer is warranted.

Keywords: adjuvant treatment, breast cancer, gene vaccines, immunotherapy, virus-like replicon particles

\section{Introduction}

The management of breast cancer currently relies on surgery, chemotherapy and radiotherapy. Despite recent advances in clinical management of breast cancer once metastasis has occurred, the probability of a complete cure is greatly reduced. Of the women who have no detectable lymph node metastases at the time of diagnosis, up to onethird later develop metastases [1]. In patients with metastatic disease that does not respond to radiotherapy or chemotherapy, immunotherapy may offer an additional form of cancer control [2-4]. Clinical trials of trastuzumab, a monoclonal antibody specific for HER2/neu, have demonstrated the utility of an immunologic approach for breast cancers that overexpress this gene [5-7]. A drawback to 'passive' immunotherapy using monoclonal antibodies is that the effect is short-lived. An alternative approach is active vaccination that could induce neu-specific cytotoxic $T$ cells with the ability to control the growth of the primary tumor and metastases. However, unlike passive immunotherapy whose effectiveness quickly wanes, effector and memory $T$ cells induced by vaccination may remain present and be able to respond to any metastatic cells expressing HER2/neu that arise after treatment.

HER2/neu is an excellent target for gene vaccines, and several preclinical studies have shown the effectiveness of plasmid vaccines encoding neu in murine models [8-16]. Using a plasmid markedly different from those previously described [8-16], we created an effective gene vaccine against HER2/neu [17]. The previously described ELVIS plasmid vaccine construct for HER2/neu contained the cDNA of a replicon RNA from the Alphavirus Sindbis

$\overline{\mathrm{BSA}}=$ bovine serum albumin; FACS = fluorescence-activated cell sorting; FCS = fetal calf serum; FITC = fluorescein isothiocyanate; HA = hemagglutinin; IFN = interferon; IU = infectious units; MEM = modified Eagle's medium; MMTV= mouse mammary tumor virus; PBS = phosphate-buffered saline; VEE = Venezuelan equine encephalitis virus; VRP = virus-like replicon particles. 
$[18,19]$. The replicon RNA contained the replication/transcription genes of the parent virus, but the structural protein genes were replaced by the gene for rat neu. From this plasmid construct, the replicon RNA is synthesized in the nucleus of the host cell and is transported to the cytoplasm for replication and transcription. The neu gene product is produced at high levels in the cytosol. Since the structural protein genes from the parent virus are not encoded by the replicon, progeny infectious Sindbis virions are not generated [20-22].

Alternatives to Alphavirus replicon plasmid vaccines $[17,19,23-25]$ are Alphavirus-based virus-like replicon particles (VRP). As already mentioned, the replicon RNA does not contain the structural genes from the parent virus. It is therefore a single-cycle, propagation-defective RNA and replicates only within the cell into which it is introduced. To generate VRP from an attenuated strain of the Alphavirus Venezuelan equine encephalitis virus (VEE), the replicon RNA is packaged into particles by co-transfecting the replicon RNA and two separate helper RNAs, which together encode the full complement of VEE structural proteins [26]. Although the VRP can infect target cells in culture or in vivo, and can express the foreign gene to a very high level, the VRP are defective since they lack critical portions of the VEE genome - they lack the VEE structural protein genes necessary to produce infectious virus particles capable of spreading to other cells $[21,27]$.

Several reports have demonstrated that VRP are extremely effective vaccine vectors [28-39]. The VEE VRP vaccine vectors are particularly attractive because the VEE envelope glycoproteins target the VRP to cells of lymphoid tissue [40], because they can be administered multiple times [39], because they induce both cellular and humoral immune responses, and because pre-existing immunity to VEE in humans should not be problematic since the incidence of VEE infection is low.

In the current study, we sought to determine whether vaccination with VEE-derived VRP containing the gene for HER2/neu would inhibit tumor growth in prevention models in which HER2/neu-expressing tumor cells had been injected either into a mammary fat pad or intravenously. We also sought to determine whether vaccination could prevent spontaneous tumorigenesis in HER2/neu transgenic mice. VRP-neu vaccination induced antigen-specific CD8+ $\mathrm{T}$-cell and $\operatorname{lgG}$ responses that corresponded with the lack of tumor growth in both tumor models. In light of the clinical benefit of trastuzumab, a safe and effective vaccine that can induce cellular and humoral immunity, VRP-neu warrants clinical evaluation.

\section{Materials and methods}

\section{Tumor cell line and reagents}

The A2L2 cell line that expresses high levels of rat HER2/ neu has been previously described in detail [17]. The A2L2 cell line has consistently expressed high levels of HER2/ neu for more than 5 years and consistently induces tumors in Balb/c mice when injected into a mammary fat pad or intravenously. The A2L2 cell line was maintained in Eagle's MEM containing 5\% FCS, sodium pyruvate, nonessential amino acids, L-glutamine, and vitamins (GIBCO, Carlsbad, CA, USA). The monolayer cultures were subdivided at approximately $75 \%$ confluence by treatment for $1-3 \mathrm{~min}$ with $0.25 \%$ trypsin and $0.02 \%$ EDTA at $37^{\circ} \mathrm{C}$.

\section{Virus-like replicon particles}

The pSV2-neu plasmid containing the gene for rat HER2/ neu was provided by Dr Mien-Chie Hung (The University of Texas MD Anderson Cancer Center, Houston, TX, USA). VEE VRP were constructed at AlphaVax, Inc. (Research Triangle Park, NC, USA) according to the published procedure [26]. Control VRP containing the gene for A/PR/8/34 influenza hemagglutinin (HA) were also prepared following the same procedure. VRP preparations were screened in a sensitive in vitro Vero cell cytopathic effect assay for the detection of replication competent virus. Prior to their use in these studies, the preparations were shown to be devoid of detectable replication competent virus.

\section{Flow cytometry}

A2L2 cells were incubated for 1 hour at $37^{\circ} \mathrm{C}$ with either immune serum or control serum diluted in PBS. FITClabeled goat anti-mouse lgG diluted 1:1000 in PBS was added to the cells and incubation was continued for 1 hour at $37^{\circ} \mathrm{C}$. The cells were washed three times in PBS and were analyzed by flow cytometry using an EPICS Profile Analyzer (Beckman Coulter, Inc., Fullerton, CA, USA).

\section{Mice}

Female Balb/c mice, aged 6-8 weeks, were obtained from the Frederick Cancer Research Facility (Frederick, MD, USA). Mice were allowed to acclimate for at least 1 week before use. Six-week-old MMTV-c-neu transgenic mice were obtained from Charles River Laboratories Inc. (Wilmington, MA, USA). This strain of mice is called the 'Oncomouse' by Charles River Laboratories due to the spontaneous generation of breast cancer. These mice are of the FVB/N strain, and the transgene is the 'activated' rat c-neu oncogene preceded by the MMTV promoter [41].

\section{Vaccination with VRP}

Mice were vaccinated subcutaneously in the hind foot pad with VRP suspended in $50 \mu \mathrm{lnormal}$ saline. Repeat vaccinations, when administered, were performed using alternate hind feet. Tail vein blood was removed and tumor challenge performed 2 weeks after the final vaccination. 
Serum was separated from the blood by centrifugation after overnight storage at $4^{\circ} \mathrm{C}$.

\section{Mammary fat pad tumor prevention model}

A2L2 cells were harvested from subconfluent cultures with trypsin and EDTA as described earlier. The cells were washed once in serum-containing culture medium and were washed once in PBS. Mice were anesthetized by inhalation of isoflurane using a special apparatus developed by the veterinarians at MD Anderson Cancer Center. The fur was shaved over the lateral thorax, and a 5-mm-long incision was made to reveal mammary fat pad 2 as previously described [42]. A 0.1-ml sample containing $2.5 \times 10^{4}$ A2L2 cells in normal saline was injected into the fat pad. The incision was closed with a wound clip. Wound clips that had not already fallen off were removed after 7 days. The mice were then observed daily and their tumors measured in perpendicular directions with a pair of calipers. Mice with tumors $10 \mathrm{~mm}$ in the greatest dimension were killed according to our approved Institutional Animal Care and Use protocol. At the termination of the experiment, all mice were killed by $\mathrm{CO}_{2}$ inhalation and all tumors were excised and weighed.

\section{Experimental metastasis prevention model}

A $0.1-\mathrm{ml}$ sample containing $2.5 \times 10^{4} \mathrm{~A} 2 \mathrm{~L} 2$ cells in normal saline was injected into the tail vein of each immunized mouse. The mice were killed 30 days later, and the surface lung metastases in each animal were counted.

\section{Tetramer analysis of immune spleen cells}

A K(d) tetramer containing the peptide sequence PYVSRLLGI [43] was prepared by the National Institutes of Health Tetramer Facility at Emory University (Atlanta, GA, USA). The incorporated peptide was synthesized at the peptide synthesis facility of MD Anderson Cancer Center. We received a $\mathrm{K}(\mathrm{d})$ tetramer specific for $\mathrm{A} / \mathrm{PR} / 8 / 34$ influenza HA containing the peptide IYSTVASSL from Linda Sherman at the Scripps Research Institute (La Jolla, CA, USA) [44]. A single-cell suspension of the spleen from a naïve mouse was prepared in R10S medium (RPMI 1640, 10\% HI-FCS [Summit Biotechnology, Fort Collins, CO, USA], $1 \%$ nonessential amino acids, $100 \mathrm{mM}$ MEM sodium pyruvate, $2 \mathrm{mM} \mathrm{L}$-glutamine, $100 \mathrm{U} / \mathrm{ml}$ penicillin, $1 \mathrm{ml}$ streptomycin, and $50 \mathrm{mM}$ 2-mercaptoethanol) by gently swirling the spleen between frosted glass slides.

Debris was removed from the cell suspension by filtration through nylon mesh into a $10-\mathrm{ml}$ centrifuge tube. The cell suspension was centrifuged for $10 \mathrm{~min}$ at $700 \times g$ and the pellet resuspended in $5 \mathrm{ml} \mathrm{ACK}$ solution $\left(0.15 \mathrm{M} \mathrm{NH}_{4} \mathrm{Cl}\right.$, $1.0 \mathrm{mM} \mathrm{KHCO}_{3}, 0.01 \mathrm{mM} \mathrm{NaEDTA}$, pH adjusted with $1 \mathrm{~N}$ $\mathrm{HCl}$ to 7.2-7.4) before being gently rocked for $5 \mathrm{~min}$ to lyse red blood cells. An additional $5 \mathrm{ml}$ R10S medium was added to the cell suspension, and the cells were washed once with R10S medium. The naïve spleen cells were cultured with either PYVSRLLGI or IYSTVASSL $(70 \mathrm{ng} / \mathrm{ml})$ on a rocker for 2 hours at $37^{\circ} \mathrm{C}$ and were $\gamma$-irradiated with 20 Gray.

The mice were vaccinated three times with a 2-week interval with $10^{6}$ infectious units (IU) VRP-neu or $10^{6}$ IU VRP$H A$, and the immune spleens were harvested 3 weeks after the final vaccination. The immune spleens were prepared to produce a single cell suspension in R10S medium and were co-cultured with the peptide-pulsed stimulator cells at a ratio of one stimulator to eight responders. The cell mixture was cultured for 7 days at $37^{\circ} \mathrm{C}$, washed, and was resuspended in FACS buffer (PBS with 1\% BSA) at a concentration of $5 \times 10^{7} \mathrm{cells} / \mathrm{ml}$. Twenty microliters of the cell mixtures were added to $20 \mu \mathrm{lPE}$-conjugated Her2/neuspecific or HA-specific tetramers to make the final dilutions of the tetramers 1:50,1:100, and 1:200. One microliter of PerCP-conjugated anti-mouseCD3e (PharMingen, San Diego, CA, USA) and FITC-conjugated anti-mouse CD8a (Caltag, Burlingame, CA, USA) was added to the mixture and incubated for 1 hour at $4^{\circ} \mathrm{C}$ in the dark. The cells were then suspended in $150 \mu$ l FACS buffer and transferred to a polystyrene round-bottomed tube. The cells were washed twice with FACS buffer and suspended in $200 \mu \mathrm{l}$ of $1 \%$ paraformaldehyde in PBS.

List mode data were acquired with a FACScan (BD Biosciences, San Jose, CA, USA). Dead cells and monocytes were excluded from the analysis by forward scatter and side scatter gating. A total of 10,000-30,000 events were typically acquired, and compensation was optimized using unstained cells, cells stained with only PerCP-conjugated anti-mouse CD3e, cells stained with only FITC-conjugated anti-mouseCD8a and cells stained with only PE-conjugated anti-mouse CD4. The $\mathrm{CD}^{+}$cells were gated from the total population of live cells, and the $\mathrm{CD}^{+}$cells were gated from the $\mathrm{CD}^{+}$cells. From the $\mathrm{CD}^{+}$cells and the CD8 double-positive cells, the percentages of PE-tetramerpositive cells were calculated. Isotype controls for the anti$\mathrm{CD} 3 \mathrm{e}$ and anti-CD8a were subtracted from the acquired data. List mode files were analyzed using CELLQUEST software (BD Biosciences, San Jose, CA, USA).

Intracellular interferon- $\gamma$ analysis of immune spleen cells The procedure for this technique was obtained from PharMingen, whose reagents were used whenever possible. Spleens from VRP-neu-immunized and VRP-HA-immunized mice were prepared as already described for tetramer analysis. The spleen cells were stimulated with PYVSRLLGI at a concentration of $70 \mathrm{ng} / \mathrm{ml}$ at $37^{\circ} \mathrm{C}$ in R10S medium for 5 days as described. On the sixth day, the cells were suspended at $2 \times 10^{6} / \mathrm{ml}$ in R10S medium containing $10 \mathrm{ng} / \mathrm{ml}$ phorbol-12-myristate acetate (Sigma-Aldrich, St Louis, MO, USA) and $250 \mathrm{ng} / \mathrm{ml}$ ionomycin (Sigma-Aldrich). Brefeldin (1 
$\mu \mathrm{l} / \mathrm{ml}$; Sigma-Aldrich) was added at the same time to block cytokine secretion. The cells were washed after 5 hours and resuspended at $10^{7} \mathrm{cells} / \mathrm{ml}$ in staining buffer (Dulbecco's PBS without $\mathrm{Mg}^{2+}$ or $\mathrm{Ca}^{2+}, 1 \%$ heat-inactivated FCS, w/v $0.09 \%$ sodium azide; $\mathrm{pH}$ adjusted to $7.4-7.6$ ). The cells were then incubated for 15 min with purified 2.4 G2 antibody $10 \mu \mathrm{g} / \mathrm{ml}$ (PharMingen) to block nonspecific staining by fluorochrome-conjugated antibodies via Fc receptors. The cells were washed twice with staining buffer, and $10^{6}$ cells were stained with $1 \mu \mathrm{g}$ FITC-labeled anti-mouse CD8a and PerCP-labeled anti-mouse CD3e (PharMingen) in $50 \mu \mathrm{l}$ staining buffer at $4^{\circ} \mathrm{C}$ for $30 \mathrm{~min}$. The cells were again washed twice with staining buffer, followed by fixation and permeabilization with Perm/Wash (Cytofix/Cytoperm Kits; PharMingen) for $20 \mathrm{~min}$ at $4^{\circ} \mathrm{C}$. The cells were washed twice and resuspended in $50 \mu \mathrm{l}$ of the same solution. PE-conjugated anti-interferon (IFN)- $\gamma$ monoclonal antibody $(0.5 \mu \mathrm{g} /$ $10^{6}$ cells; PharMingen) was added and the suspension was incubated for $30 \mathrm{~min}$ at $4^{\circ} \mathrm{C}$. The cells were then washed twice with Perm/Wash solution and resuspended in staining buffer.

The FACScan was used to analyze the percentage of intracellular IFN- $\gamma$-containing cells among the $\mathrm{CD}^{+}$and $\mathrm{CD}^{+}$ cells. Isotype controls for anti-CD3a, anti-CD8e, and antiIFN- $\gamma$ (PharMingen) were subtracted from the acquired data.

\section{ELISPOT analysis of IFN- $\gamma$ production by immune spleen cells}

The procedure for the ELISPOT technique was obtained from PharMingen, whose reagents were used whenever possible. The wells of an ELISPOT plate (CTL Immunospot plate; Cellular Technology Ltd, Cleveland, OH, USA) were coated overnight at $4^{\circ} \mathrm{C}$ with $100 \mu \mathrm{l}$ anti-mouse IFN- $\gamma$ (2 $\mu \mathrm{g} / \mathrm{ml}$; PharMingen) diluted at 1:200 in coating buffer (PBS, pH 7.2). The coated wells were washed with blocking solution (R10S medium), fresh blocking solution was added to each well, and then the plate was incubated for 2 hours at room temperature. The blocking solution was then discarded and $100 \mu \mathrm{l}$ A2L2 cells $\left(2 \times 10^{5}-1 \times 10^{6}\right)$ was added to each well of the ELISPOT plate.

Immune spleens were dissected from vaccinated mice and were prepared as already described for tetramer analysis. Increasing numbers of spleen cells $\left(5 \times 10^{6}-2 \times 10^{7}\right)$ in 100 $\mu \mathrm{L} 10 \mathrm{~S}$ medium were added to the wells, and the plate was incubated for 24 hours at $37^{\circ} \mathrm{C}$ in a $5 \% \mathrm{CO}_{2}$ atmosphere at $99 \%$ humidity. Wells containing only spleen cells served as negative controls, and spleen cells from VRP-neu-vaccinated mice cultured overnight with $5 \mu \mathrm{g} / \mathrm{ml}$ concanavalin A (Sigma-Aldrich) served as a positive control. The cell suspension was aspirated, and the wells were washed twice with deionized water and were then soaked with deionized water for $5 \mathrm{~min}$. The wells were washed three times with wash buffer I (PBS containing 0.05\% Tween-20).
The detection antibody, biotinylated anti-mouse IFN- $\gamma$ (PharMingen), was diluted to $2 \mu \mathrm{g} / \mathrm{ml}$ in dilution buffer (PBS containing $10 \% \mathrm{FBS}$ ), and $100 \mu \mathrm{l}$ was added to each well. The plate was incubated at room temperature for 2 hours, and the wells were washed three times with buffer I. Avidinhorseradish peroxidase reagent (PharMingen) was diluted to 1:100 in dilution buffer, and $100 \mu \mathrm{l}$ was added to each well, which was then incubated at room temperature for 1 hour. The wells were washed four times with wash buffer I and twice with wash buffer II (PBS). A stock solution containing $100 \mathrm{mg}$ 3-amino-9-ethyl-carbazole (Sigma) dissolved in 10

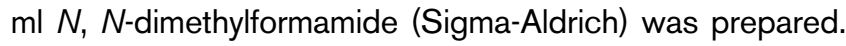
The final substrate solution was made by adding $333 \mu \mathrm{l}$ 3amino-9-ethyl-carbazole stock solution to $10 \mathrm{ml}$ of $0.1 \mathrm{M}$ sodium acetate ( $\mathrm{pH}$ 5.0), followed by filtering through a $0.45-\mu \mathrm{m}$ filter. Five microliters of $30 \% \mathrm{H}_{2} \mathrm{O}_{2}$ was added to the substrate solution immediately before use.

One hundred microliters of the final substrate solution was added to each well, and the plate was incubated in the dark for 5-60 $\mathrm{min}$ at room temperature. The reaction was stopped by washing the wells with deionized water. The plate was air-dried overnight at room temperature in the dark and sent to ZellNet Consulting, Inc. http://www.zell net.com, where the spots were enumerated automatically using an ImmunoSpot Series I analyzer (BD Biosciences). If overlapping spots (confluence) were present in the wells, the number of spots in a nonconfluent area of that well was determined. To estimate the total number of spots in each well with confluence, the following equation was used: total spot number $=$ spot count $+2 \times($ spot count $\times \%$ confluence / [100\% - \% confluence]).

\section{Statistical analysis}

Student's $t$ test was performed using Prism 4.0 Graphpad Software (San Diego, CA, USA). Statistical analysis, power analysis and the sample size per group were evaluated and found to be statistically acceptable by Dr Lyle Broemling (Associated Professor of Biostatistics, The University of Texas MD Anderson Cancer Center).

\section{Results \\ Induction of antigen-specific IgG by vaccination with VRP-neu}

Groups of Balb/c mice ( $n=5$ per group) were vaccinated once subcutaneously in one hind leg footpad with either $10^{6} \mathrm{IU}$ VRP-neu or $10^{6} \mathrm{IU}$ VRP-HA suspended in PBS. The HER2/neu-specific humoral response of serum pooled from mice in each group was measured 14 days later by flow cytometry using A2L2 cells. Compared with the mice vaccinated with VRP-HA, the mice vaccinated with VRPneu had a strong IgG response (Fig. 1). Pre-immune sera for both groups were nonreactive with A2L2 cells, and immune sera from both vaccinated groups were nonreac- 


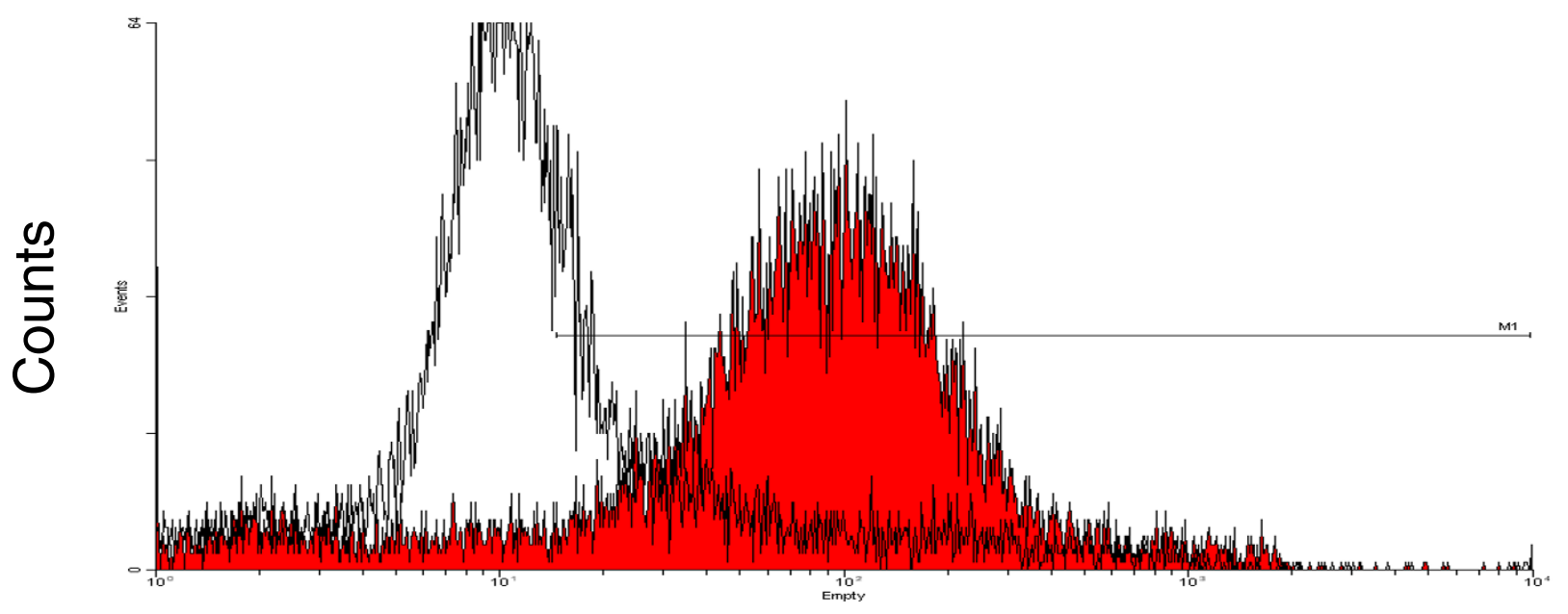

Fluorescence

Flow cytometric analysis of A2L2 cells with serum from mice vaccinated with virus-like replicon particles (VRP)-neu or VRP-hemagglutinin (HA). Serum was collected 2 weeks after a single vaccination of Balb/c mice with $10^{6}$ IU VRP-neu (filled curve) or $10^{6}$ IU VRP-HA (open curve). The primary serum was diluted with PBS (1:100), and FITC-labeled goat anti-mouse IgG diluted in PBS (1:1000) was used as the secondary antibody.

tive with 66.3 cells, the parental cell line from which A2L2 was derived by transfection with neu (data not shown).

\section{Protection from tumor challenge in a mammary fat pad prevention model following vaccination with VRP-neu}

Groups of mice ( $n=7$ per group) were vaccinated subcutaneously with $10^{5} \mathrm{IU}$ or $10^{6} \mathrm{IU}$ VRP-neu or with $10^{6} \mathrm{IU}$ VRP-HA three times at 14-day intervals. Two weeks after the final vaccination, the mice were challenged with $2.5 \times$ $10^{4} \mathrm{~A} 2 \mathrm{~L} 2$ cells injected into a mammary fat pad. Five weeks after tumor challenge, the largest tumor dimension was measured and the mice were killed. If a tumor was present, its mass was determined. All of the mice vaccinated with VRP-HA had a measurable tumor, whereas only one mouse in each group vaccinated with $10^{6} \mathrm{IU}$ VRP-neu or $10^{5} \mathrm{IU}$ VRP-neu had a measurable tumor (Fig. 2a,2b). These findings clearly demonstrate that vaccination three times with either $10^{5} \mathrm{IU}$ or $10^{6} \mathrm{IU}$ VRP-neu protected mice from challenge with A2L2 cells. VRP-HA failed to provide protection for any of the mice, and therefore the protective effect was specific for the vaccine containing the gene for HER2/neu.

\section{Determination of the minimal effective vaccine dose in two tumor prevention models}

Because vaccination three times with $10^{5}$ IU VRP-neu prevented tumor growth in a mammary fat pad, we next determined the minimum number of VRP-neu particles and the minimum number of vaccinations necessary to significantly inhibit tumor growth. In the mammary fat pad prevention model, vaccination twice with $10^{5} \mathrm{IU}$ VRP-neu or vaccination three times with $10^{4} \mathrm{IU}$ VRP-neu completely prevented tumor growth in many mice and significantly reduced the tumor mass in the entire group compared with the tumor mass of the mice vaccinated three times with VRP-HA (Fig. 3a). Identical results were obtained in the experimental lung metastasis prevention model, in which mice were injected with A2L2 cells intravenously in the tail vein after vaccination (Fig. 3b). These results demonstrate that, in both tumor models, vaccination three times with $10^{4} \mathrm{IU}$ VRP-neu or twice with $10^{5} \mathrm{IU}$ VRP-neu significantly reduced the tumor mass and lung metastasis. In addition, several mice in each vaccinated group were tumor free in mammary tissue or lungs.

\section{Vaccination of MMTV-c-neu transgenic mice}

MMTV-c-neu transgenic mice contain the activated rat neu gene under the control of the MMTV promoter and spontaneously develop neu+ breast tumors within 110-120 days [45]. Without intervention, all of the mice die of breast cancer. We vaccinated groups of mice ( $n=10$ per group) three times at 14-day intervals with $10^{6}$ IU VRP-neu or $10^{6}$ IU VRP-HA and determined the effect on survival. Eight of the 10 mice vaccinated with VRP-HA were killed by 140 days owing to moribundity, and the remaining two mice were killed on day 195 (Fig. 4). None of the mice vaccinated with VRP-neu showed any sign of illness at 240 days, and breast tumors were not evident on palpation. The mice in the VRP-neu-vaccinated group were killed at this time, and gross pathologic examination of the breasts fol- 
Figure 2

(a)

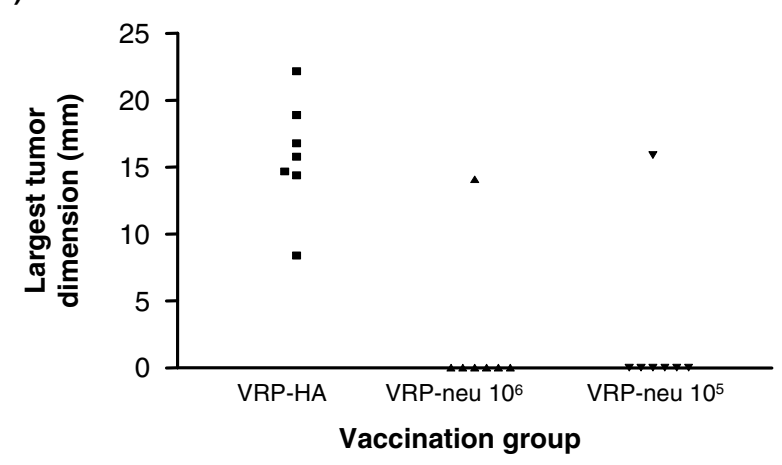

(b)

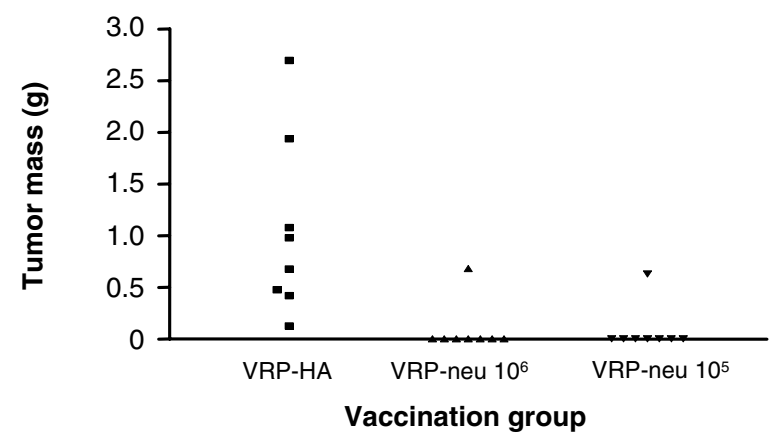

Protection from tumor challenge after vaccination with virus-like replicon particles (VRP)-neu. Groups of seven or eight mice were vaccinated three times at 2-week intervals with VRP-neu or VRP-

hemagglutinin (HA). Two weeks after the final vaccination, the mice were challenged with A2L2 cells injected into a mammary fat pad. Five weeks after the tumor challenge, (a) the largest dimension of each tumor was measured and (b) the mice were killed and the mass of the tumor in each animal was determined.

lowing retraction of the skin did not reveal any tumors. These results demonstrate that vaccination with VRP-neu prevented spontaneous formation of tumor in the breasts of neu transgenic mice and that tolerance to the neu transgene was broken by vaccination with VRP-neu.

\section{Induction of antigen-specific IgG by vaccination of MMTV-c-neu transgenic mice with VRP-neu}

Immune serum was drawn from mice described at 133 days or 55 days after the third vaccination with VRP-neu or VRP-HA (Fig. 4). Flow cytometric analysis of the immune sera using A2L2 cells demonstrated that vaccination with VRP-neu induced a strong $\lg G$ response that was evident at dilutions of 1:25 (Fig. 5a) and 1:100 (Fig. 5b). Vaccination with the control VRP-HA failed to induce a neu-specific antibody response (Fig. 5a,5b). These findings indicate that vaccination with VRP-neu induced humoral immunity to the protein product of the neu-transgene in neu-transgenic mice, thus breaking any existing tolerance to $p 185$.

\section{Tetramer analysis of $\mathrm{CD}^{+} \mathbf{T}$ cells following vaccination} with VRP-neu or VRP-HA

Ikuta and colleagues [43] identified a K(d)-restricted peptide for mouse HER2/neu. The identical sequence (PYVSRLLGI) is present in rat HER2/neu. We therefore ordered a tetramer containing this sequence from the National Institutes of Health Tetramer Facility at Emory University. A K(d) tetramer specific for A/PR/8/34 influenza HA was used as a positive control for VRP-HA-vaccinated mice. Balb/c mice were vaccinated three times at 2 -week intervals with VRP-neu or VRP-HA, and the spleens from two mice were collected 3 weeks after the third injection. We found that $2.38 \%$ of the pooled spleen cells from the mice that had been vaccinated three times with VRP-neu were stained by both the anti-CD8 antibody and the HER2/neu tetramer (Table 1). This value is in excellent agreement with the percentage of dual-positive cells from mice that had been vaccinated with VRP-HA and stained with the HA tetramer (2.79\%). In contrast, the percentage of dual-positive cells from the mice that had been vaccinated with VRP-HA and stained with the HER2/neu tetramer was only $0.22 \%$, and the percentage from the mice that had been vaccinated with VRP-neu and stained with the HA tetramer was only $0.37 \%$. These results clearly demonstrate that vaccination with VRP-neu produced antigen-specific CD8+ T cells.

\section{Intracellular IFN- $\gamma$ analysis of $\mathbf{C D}^{+} \mathbf{T}$ cells following} vaccination with VRP-neu or VRP-HA

An alternative assay to tetramer analysis is measurement of the percentage of CD8+ T cells that also contain intracellular IFN- $\gamma$ after in vitro stimulation with an antigenic peptide. We therefore vaccinated Balb/c mice three times at 2week intervals with VRP-neu or VRP-HA, and then removed the spleens 3 weeks after the third injection. The in vitro culture procedure was similar to that used for tetramer analysis except that the peptide PYVSRLLGI was cultured directly with the immune spleen cells rather than with naïve spleen cells. We found that $2.80 \%$ of the spleen cells from the mice that had been vaccinated three times with VRPneu stained positive for intracellular IFN- $\gamma$ (Fig. 6a and Table 2) compared with only $0.27 \%$ for spleen cells from mice vaccinated with VRP-HA (Fig. $6 \mathrm{~b}$ and Table 2). This percentage $(2.80 \%)$ is in excellent agreement with that of tetramer-positive cells after vaccination with VRP-neu (2.38\%) (Table 1).

\section{Analysis of immune spleen cells by IFN- $\gamma$ ELISPOT after vaccination with VRP-neu or VRP-HA}

We vaccinated Balb/c mice three times at 2-week intervals with VRP-neu or VRP-HA and removed the spleens 3 weeks after the third injection. The number of spleen cells secreting IFN- $\gamma$ in response to overnight co-culture with 
(a)

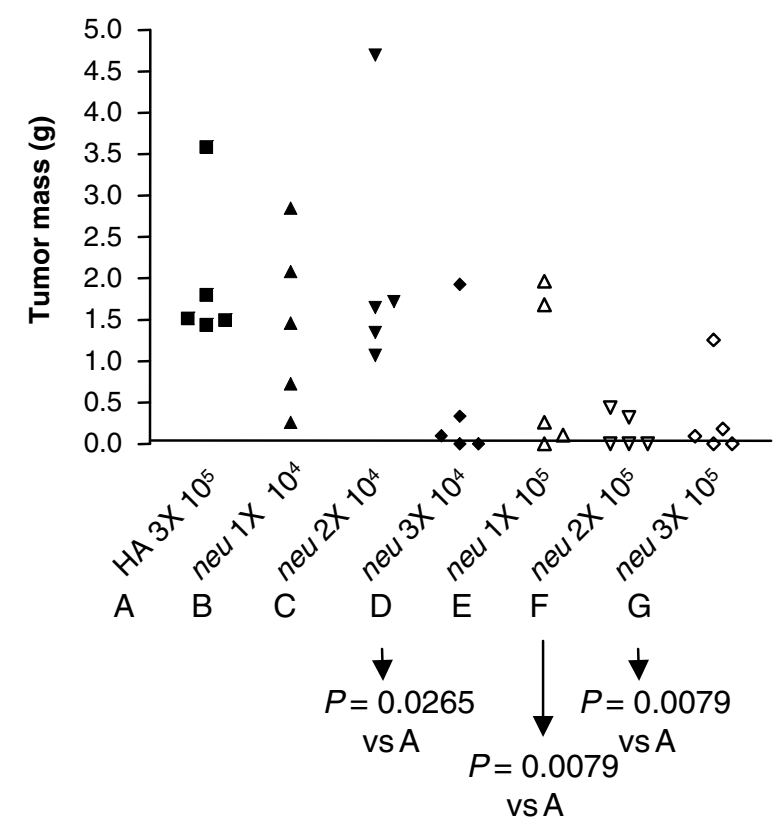

(b)

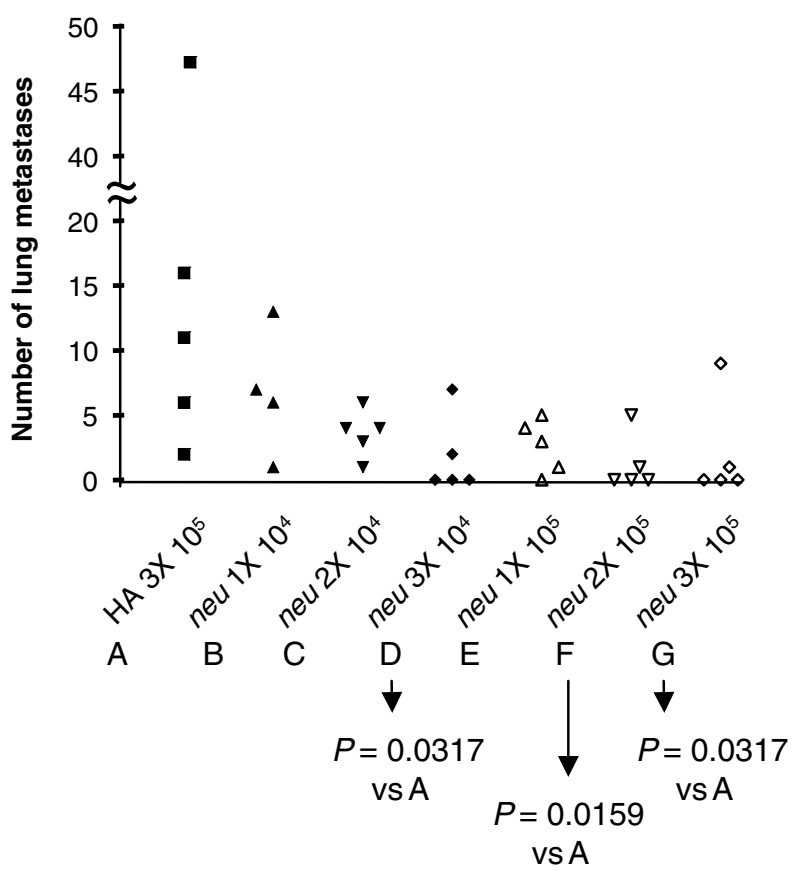

Minimal effective vaccine dose in two tumor prevention models. Groups of four or five mice were vaccinated once, twice or three times (1X, $2 X$, or $3 X)$ at 2-week intervals with virus-like replicon particles (VRP)-neu or VRP-hemagglutinin (HA) (104 IU or $10^{5}$ IU). Two weeks after the final vaccination, the mice were challenged with A2L2 cells injected into a mammary fat pad or intravensouly. The mice were killed 5 weeks after the tumor challenge. (a) The mass of the mammary tumors, if present, was determined in the mammary fat pad prevention model group, and (b) the number of surface metastases on the lungs was determined in the experimental lung metastasis prevention model group.

\section{Figure 4}

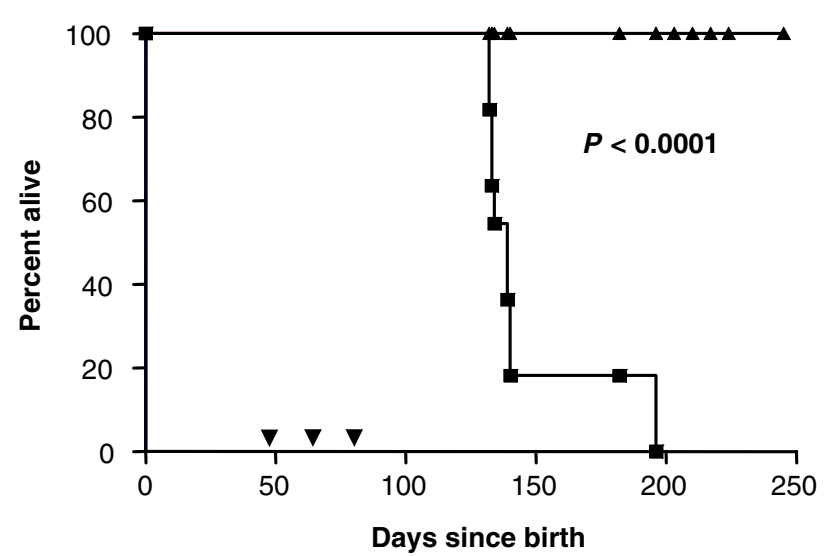

Inhibition of spontaneous tumor formation by vaccination with virus-like replicon particles (VRP)-neu. Groups of MMTV-c-neu transgenic mice ( $n=10$ per group) were vaccinated three times $(\boldsymbol{\nabla})$ at 2 -week intervals with $10^{6}$ IU VRP-neu $(\boldsymbol{\Delta})$ or $10^{6}$ IU VRP-hemagglutinin (HA) ( $(\mathbf{\square})$. The mice vaccinated with VRP-HA were killed when moribund, and the mice vaccinated with VRP-neu were killed at 240 days.
A2L2 cells in an ELISPOT assay were then determined. At all three effector-to-stimulator ratios, vaccination with VRPneu resulted in a statistically significant increase in the number of spots per $10^{6}$ spleen cells (Table 3 ). This finding demonstrates that secretion of IFN- $\gamma$ in response to co-culture with A2L2 cells was dependent on vaccination with VRP-neu and did not result from vaccination with the control VRP-HA.

\section{Discussion}

Although more than a decade has elapsed since the original descriptions of gene vaccines [46,47], a clinically approved gene vaccine for either an infectious disease or for cancer has yet to be developed. Gene vaccines containing elements of the Alphaviruses VEE, Sindbis virus and Semliki Forest virus offer substantial clinical potential and safety $[22,27]$. Vaccine vectors incorporating genetic elements of Alphaviruses can be divided into two major categories [48]: expression plasmids containing viral genes that are essential for replication and transcription of the positive-strand RNA genome of the viruses [18,24], and infectious but replication-incompetent viral particles in which the genes for the viral structural proteins have been 
Figure 5

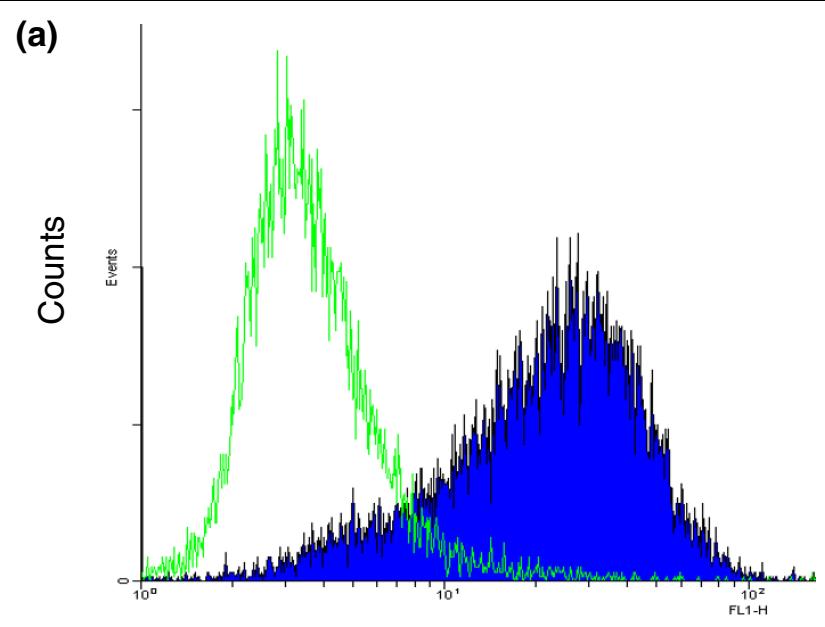

Fluorescence

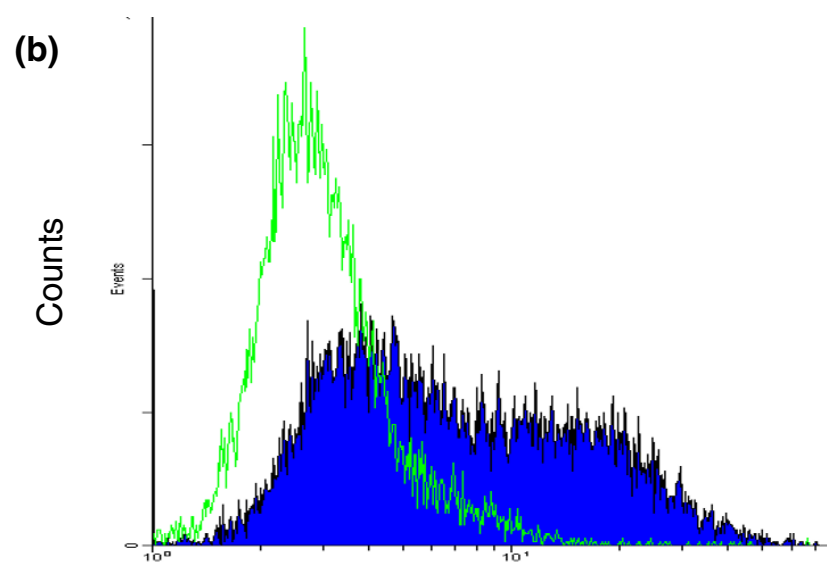

Fluorescence

Flow cytometric analysis of A2L2 cells with sera from MMTV-c-neu mice vaccinated with virus-like replicon particles (VRP)-neu or VRPhemagglutinin (HA). Immune serum from the mice (described in Fig. 4) was drawn at 133 days. The serum was analyzed at dilutions of (a) 1:25 and (b) 1:100. Filled curve, sera from VRP-neu-vaccinated mice; open curve, sera from VRP-HA-vaccinated mice. The secondary antibody, FITC-labeled goat anti-mouse lgG, was diluted in PBS (1:1000).

replaced by the gene for a protein antigen [20-22]. We have previously described a gene vaccine for HER2/neu of the first category [17]. In the present article, we describe results of a gene vaccine for HER2/neu of the second category.

We report here that VRP vaccine vectors derived from an attenuated strain of VEE containing the gene for rat HER2/ neu were highly immunogenic when used to vaccinate both conventional mice and mice transgenic for the rat neu gene. Immune serum from mice vaccinated once with VRPneu was reactive with $\mathrm{A} 2 \mathrm{~L} 2$ cells, demonstrating induction of an antigen-specific $\lg G$ response, whereas serum from mice that had been vaccinated with VRP-HA was nonreactive (Fig. 1).

To determine whether vaccination with VRP-neu could protect mice from challenge with a breast cancer cell line engineered to overexpress HER2/neu, mice that had been vaccinated three times with either VRP-neu or VRP-HA were injected in a mammary fat pad with A2L2 cells. Vaccination with either $10^{5} \mathrm{IU}$ or $10^{6} \mathrm{IU}$ VRP-neu protected all but one mouse in each group from developing tumors (Fig. 2). Because our previous experiment demonstrated that a single vaccination with $10^{6}$ IU VRP-neu induced an IgG response, we next vaccinated mice once, twice or three times with $10^{4} \mathrm{IU}$ or $10^{5} \mathrm{IU}$ VRP-neu or the control VRPHA. Vaccination three times with $10^{4}$ IU VRP-neu ( $P=$ $0.0265)$ or twice with $10^{5}$ IU VRP-neu $(P=0.0079)$ was sufficient to prevent tumor growth of A2L2 cells injected into a mammary fat pad (Fig. 3a). Mice similarly vaccinated were also challenged with A2L2 cells injected intravenously in the tail vein. Vaccination three times with $10^{4}$ IU VRP-neu $(P=0.0317)$ or twice with $10^{5}$ IU VRP-neu $(P=0.0159)$ prevented tumor growth in the lungs (Fig. 3b). Some mice in the vaccine groups had no visible lung metastases 5 weeks after the tumor challenge. This finding clearly demonstrates that vaccination with VRP-neu prevented tumor growth in two tumor prevention models.

There is an important point to be considered regarding our experimental models. We are vaccinating mice with the gene for rat neu and we are challenging mice with a cell line also overexpressing the gene for rat neu. We must therefore consider the possibility that mice recognized rat p185 (the protein product of the HER2/neu gene) as a xenoantigen and that vaccination with VRP-neu merely boosted, but did not initiate, an immune response. We addressed this question by vaccinating rat neu transgenic mice, which are immunologically tolerant to rat $\mathrm{p} 185$. MMTV-c-neu transgenic mice express the rat neu transgene under the control of the murine mammary tumor virus promoter and spontaneously develop $\mathrm{Ne}^{+}$breast cancer. Vaccination of these transgenic mice with VRP-neu very clearly demonstrated $(P<0.0001)$ that the mice survived to 240 days old (Fig. 4), at which time the experiment was concluded. On postmortem examination, no tumor was detected in the breast of any mouse that had been vaccinated with VRP-neu. All mice in the control group that had been vaccinated with VRP-HA were moribund owing to extensive breast cancer by 200 days. This result is much more dramatic than our previous finding that vaccination of MMTV-c-neu transgenic mice with the Sindbis/DNA plasmid-based ELVIS replicon vector increased survival of the transgenic mice but failed to protect against tumor formation and death [17]. To determine whether vaccination of the MMTV-c-neu transgenic mice with VRP-neu induced an IgG response, as we found in Balb/c mice (Fig. 1), we tested 
Table 1

Tetramer analysis of CD8+ T cells after vaccination three times with virus-like replicon particles (VRP)-neu or VRP-hemagglutinin (HA)

\begin{tabular}{|c|c|c|c|}
\hline Vaccination & CD8+ cells (\%) & Tetramer-positive CD8+ cells (\%) & Tetramer-positive CD8+/CD8+ $(\%)$ \\
\hline \multicolumn{4}{|c|}{ neu-specific tetramer } \\
\hline VRP-neu & 15.98 & 0.38 & 2.38 \\
\hline VRP-HA & 23.06 & 0.05 & 0.22 \\
\hline \multicolumn{4}{|c|}{ HA-specific tetramer } \\
\hline VRP-neu & 16.01 & 0.06 & 0.37 \\
\hline VRP-HA & 17.46 & 0.50 & 2.79 \\
\hline
\end{tabular}

Table 2

\begin{tabular}{|c|c|c|}
\hline Vaccination & Isotype control (\%) & Interferon- $\gamma^{+} / \mathrm{CD}^{+}{ }^{+}(\%)$ \\
\hline VRP-neu & 0.10 & 2.80 \\
\hline VRP-HA & 0.14 & 0.27 \\
\hline Naïve & 0.03 & 0.39 \\
\hline
\end{tabular}

Figure 6

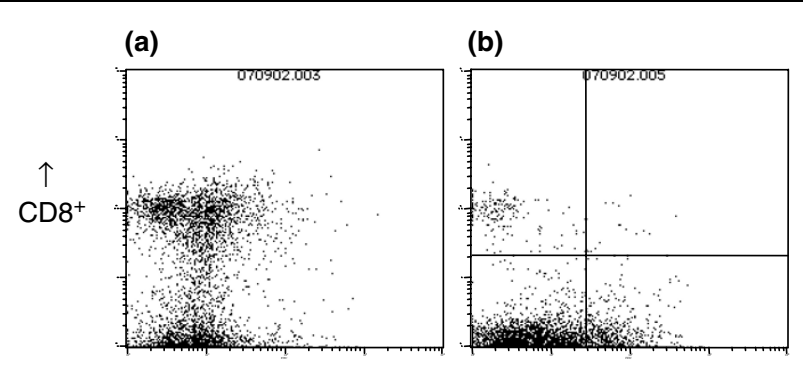

IFN- $\gamma \rightarrow$

Intracellular interferon (IFN)- $\gamma$ analysis of spleen cells from vaccinated mice. Spleen cells from mice vaccinated three times with (a) virus-like replicon particles (VRP)-neu or (b) VRP-hemagglutinin (HA) were analyzed for the presence of intracellular IFN- $\gamma$ after in vitro culture with a neu-specific peptide.

the serum of the vaccinated neu-transgenic mice at 133 days old. Vaccination with VRP-neu induced a strong, antigen-specific lgG response in these transgenic mice (Fig. 5). Vaccination with VRP-neu therefore overcame tolerance to p185 (Fig. 5).

In our present study, we performed three separate in vitro Tcell assays to determine whether vaccination with VRP-neu induces antigen-specific $\mathrm{T}$ cells. In the first assay we used tetramers containing an antigenic peptide of HER2/neu to
Table 3

Interferon- $\gamma$ ELISPOT assay after vaccination with virus-like replicon particles (VRP)-neu or VRP-hemagglutinin (HA)

\begin{tabular}{lcc} 
Effector:stimulator & $\begin{array}{c}\text { VRP-neu } \\
\text { (spots/106 cells) }\end{array}$ & $\begin{array}{c}\text { VRP-HA } \\
\text { (spots/106 cells) }\end{array}$ \\
\hline $100: 1$ & $99^{\mathrm{a}}$ & 11 \\
$50: 1$ & $126^{\mathrm{a}}$ & 17 \\
$25: 1$ & $129^{\mathrm{a}}$ & 25 \\
Effector only & 2 & 5 \\
Concanavalin A & $256^{\mathrm{a}, \mathrm{b}}$ & Not determined \\
\hline
\end{tabular}

a $P=0.05$ by Student's $t$ test.

bSpleen cells stimulated with concanavalin A as a positive control for the assay.

analyze spleen cells from mice vaccinated with VRP-neu. As a positive control we used a tetramer containing an antigenic peptide of HA. We found that $2.38 \%$ of the CD8+ spleen cells resulting from vaccination with VRP-neu were positive for tetramer binding (Table 1), a value in excellent agreement with the $2.79 \%$ of the spleen cells from VRP-HA-vaccinated mice that were positive for an $\mathrm{HA}$-specific tetramer. We further analyzed the induction of antigen-specific CD8 ${ }^{+} \mathrm{T}$ cells resulting from VRP-neu vaccination by performing intracellular IFN- $\gamma$ analysis. We found that $2.80 \%$ of $\mathrm{CD}^{+}$cells from VRP-neu-vaccinated mice were positive for intracellular IFN$\gamma$ (Table 2), a value in excellent agreement with the $2.38 \%$ tetramer-binding cells (Table 1). In the third assay we measured the number of IFN- $\gamma$ secreting cells by ELISPOT analysis (Table 3). At all three effector:stimulator ratios, the number of IFN- $\gamma$ secreting cells in the VRP-neu-vaccinated spleen cells was significantly greater than that in the VRPHA-vaccinated spleen cells.

These three independent assays clearly demonstrate that vaccination with VRP-neu induced antigen-specific CD8 ${ }^{+} \mathrm{T}$ lymphocytes. The tetramer and intracellular IFN- $\gamma$ assays further indicate that immune spleen cells were able to rec- 
ognize an antigenic peptide of p185 presented on the A2L2 cells used for the ELISPOT assay.

The in vivo and in vitro experiments described demonstrate that vaccination induced antigen-specific cell-mediated and humoral immunity, but they do not indicate the role that each type of immunity may have played in the resulting antitumor effect. Therefore, although vaccination with VRP-neu produced antigen-specific lgG in both conventional and transgenic mice, whether this antibody played a role in the antitumor effect remains unclear. Pilon and colleagues [49] reported that antibody was not required for the antitumor effect of a plasmid vaccine against HER2/neu. Lindencrona and colleagues [50] similarly induced antitumor immunity against HER2/neu in B cell-deficient mice. Although Tcell immunity alone may be sufficient in tumor prevention models in mice, a clinical trial showed that trastuzumab clearly benefited patients and increased the antitumor effect of a whole-cell vaccine to HER2/neu [51].

\section{Conclusion}

Our findings demonstrate that vaccination with VRP-neu inhibited or eliminated tumor growth in prevention models in which breast tumor cells had been injected either in the mammary fat pad or intravenously. Vaccination with VRPneu also prevented tumorigenesis in transgenic mice in which the neu gene was expressed in the breasts under the control of an MMTV promoter. Vaccination with VRP-neu induced antigen-specific $\mathrm{CD8}^{+}$, and this finding corresponded with the absence or inhibition of tumor growth. Furthermore, vaccination with VRP-neu induced antigenspecific lgG in both conventional and transgenic mice, and tolerance to HER2/neu in neu-transgenic mice was broken by vaccination with VRP-neu. These findings suggest that VRP-neu constitutes a powerful gene vaccine that induces both cellular and humoral immunity against HER2/neu. We speculate that such vaccination could be more effective than passive immunotherapy using monoclonal antibodies such as trastuzumab in patients with breast cancer.

\section{Competing interests}

MFM is an employee of AlphaVax, Inc. and has options to purchase the company's stock. None of the other authors have any financial interest in AlphaVax, Inc. or in any products that could result from this research. All of the research was conducted independently at the University of Texas MD Anderson Cancer Center and was not influenced in any way by employees or the management of AlphaVax, Inc.

\section{Authors' contributions}

The authors' contributions to this research are reflected in the order shown with the exception of LBL, who supervised all aspects of this research and the preparation of this report.

\section{Acknowledgements}

This research was supported by the US Army Medical Research and Materiel Command, Department of Defense Breast Cancer Research Program, BC980071, the WM Keck Center for Cancer Gene Therapy, and the Cancer Center Core Grant CA16672. The authors thank Galina M Kiriakova in the Department of Cancer Biology for her cooperation and outstanding technical assistance. They also thank Kate Ó Súilleabháin of the Department of Scientific Publications for expert editing of the manuscript.

\section{References}

1. Fornier M, Munster $P$, Seidman AD: Update on the management of advanced breast cancer. Oncology 1999, 13:647-658.

2. Schlom J, Kantor J, Abrams S, Tsang KY, Panicali D, Hamilton JM: Strategies for the development of recombinant vaccines for the immunotherapy of breast cancer. Breast Cancer Res Treat 1996, 38:27-39.

3. Emens LA, Jaffee EM: Toward a breast cancer vaccine: work in progress. Oncology (Huntingt) 2003, 17:1200-1211.

4. Rosenberg SA: Shedding light on immunotherapy for cancer. $N$ Engl J Med 2004, 350:1461-1463.

5. Slamon DJ, Leyland-Jones B, Shak S, Fuchs H, Paton V, Bajamonde A, Fleming T, Eiermann W, Wolter J, Pegram M, et al.: Use of chemotherapy plus a monoclonal antibody against HER2 for metastatic breast cancer that overexpresses HER2. $N$ Engl J Med 2001, 344:783-792.

6. Spigel DR, Burstein HJ: Trastuzumab regimens for HER2-overexpressing metastatic breast cancer. Clin Breast Cancer 2003, 4:329-337.

7. Piccart M, Lohrisch C, Di Leo A, Larsimont D: The predictive value of HER2 in breast cancer. Oncology 2001, 61(Suppl 2):73-82.

8. Chen Y, Hu D, Eling DJ, Robbins J, Kipps TJ: DNA vaccines encoding full-length or truncated neu induce protective immunity against neu-expressing mammary tumors. Cancer Res 1998, 58:1965-1971.

9. Chen SA, Tsai MH, Wu FT, Hsiang A, Chen YL, Lei HY, Tzai TS, Leung $\mathrm{HW}$, Jin $\mathrm{YT}$, Hsieh $\mathrm{CL}$, et al:: Induction of antitumor immunity with combination of HER2/neu DNA vaccine and interleukin 2 gene-modified tumor vaccine. Clin Cancer Res 2000, 6:4381-4388.

10. Foy TM, Bannink J, Sutherland RA, McNeill PD, Moulton GG, Smith J, Cheever MA, Grabstein K: Vaccination with Her-2/neu DNA or protein subunits protects against growth of a Her-2/ neu-expressing murine tumor. Vaccine 2001, 19:2598-2606.

11. Di Carlo E, Rovero S, Boggio K, Quaglino E, Amici A, Smorlesi A, Forni G, Musiani P: Inhibition of mammary carcinogenesis by systemic interleukin 12 or p185neu DNA vaccination in Her-2/ neu transgenic BALB/c mice. Clin Cancer Res 2001, 7:830s-837s.

12. Rovero S, Boggio K, Carlo ED, Amici A, Quaglino E, Porcedda P, Musiani $P$, Forni G: Insertion of the DNA for the 163-171 peptide of IL1-b enables a DNA vaccine encoding $\mathrm{p} 185(n e u)$ to inhibit mammary carcinogenesis in Her-2/neu transgenic BALB/c mice. Gene Ther 2001, 8:447-452.

13. Pupa SM, Invernizzi AM, Forti S, Di Carlo E, Musiani P, Nanni P, Lollini PL, Meazza R, Ferrini S, Menard S: Prevention of spontaneous neu-expressing mammary tumor development in mice transgenic for rat proto-neu by DNA vaccination. Gene Ther 2001, 8:75-79.

14. Piechocki MP, Pilon SA, Wei WZ: Complementary antitumor immunity induced by plasmid DNA encoding secreted and cytoplasmic human ErbB-2. J Immunol 2001, 167:3367-3374.

15. Mukai K, Yasutomi Y, Watanabe M, Kenjo A, Aota T, Wang L, Nishikawa H, Ishihara M, Fujita T, Kuribayashi K, Shiku H: HER2 peptide-specific $\mathrm{CD}^{+} \mathrm{T}$ cells are proportionally detectable long after multiple DNA vaccinations. Gene Ther 2002, 9:879-888.

16. Amici A, Smorlesi A, Noce G, Santoni G, Cappelletti P, Capparuccia L, Coppari R, Lucciarini R, Petrelli C, Provinciali M: DNA vaccination with full-length or truncated neu induces protective immunity against the development of spontaneous mammary tumors in HER-2/neu transgenic mice. Gene Ther 2000, 7:703-706. 
17. Lachman LB, Rao XM, Kremer RH, Ozpolat B, Kiriakova G, Price JE: DNA vaccination against neu reduces breast cancer incidence and metastasis in mice. Cancer Gene Ther 2001, 8:259-268.

18. Dubensky TW Jr, Driver DA, Polo JM, Belli BA, Latham EM, Ibanez $\mathrm{CE}$, Chada S, Brumm D, Banks TA, Mento SJ, et al.: Sindbis virus DNA-based expression vectors: utility for in vitro and in vivo gene transfer. J Virol 1996, 70:508-519.

19. Hariharan MJ, Driver DA, Townsend K, Brumm D, Polo JM, Belli BA, Catton DJ, Hsu D, Mittelstaedt D, McCormack JE, et al: DNA immunization against herpes simplex virus: enhanced efficacy using a Sindbis virus-based vector. J Virol 1998, 72:950-958.

20. Polo JM, Dubensky TW: Virus-based vectors for human vaccine applications. Drug Discov Today 2002, 7:719-727.

21. Schlesinger S, Dubensky TW: Alphavirus vectors for gene expression and vaccines. Curr Opin Biotechnol 1999, 10:434-439.

22. Rayner JO, Dryga SA, Kamrud KI: Alphavirus vectors and vaccination. Rev Med Virol 2002, 12:279-296.

23. Yamanaka R, Xanthopoulos KG: Development of improved Sindbis virus-based DNA expression vector. DNA Cell Biol 2004, 23:75-80

24. Smerdou C, Liljestrom P: Non-viral amplification systems for gene transfer: vectors based on alphaviruses. Curr Opin Mol Ther 1999, 1:244-251

25. Leitner WW, Hwang LN, DeVeer MJ, Zhou A, Silverman RH, Williams BR, Dubensky TW, Ying H, Restifo NP: Alphavirus-based DNA vaccine breaks immunological tolerance by activating innate antiviral pathways. Nat Med 2003, 9:33-39.

26. Pushko P, Parker M, Ludwig GV, Davis NL, Johnston RE, Smith JF: Replicon-helper systems from attenuated Venezuelan equine encephalitis virus: expression of heterologous genes in vitro and immunization against heterologous pathogens in vivo. Virology 1997, 239:389-401.

27. Lundstrom K: Alphavirus vectors for vaccine production and gene therapy. Expert Rev Vaccines 2003, 2:447-459.

28. Hevey M, Negley D, Pushko P, Smith J, Schmaljohn A: Marburg virus vaccines based upon alphavirus replicons protect guinea pigs and nonhuman primates. Virology 1998, 251:28-37.

29. McCluskie MJ, Davis HL, Davis NL, Caley IJ, Brown KW, Betts MR, Irlbeck DM, McGrath KM, Connell MJ, Montefiori DC, et al.: Novel strategies using DNA for the induction of mucosal immunity. Vaccination of macaques against pathogenic simian immunodeficiency virus with Venezuelan equine encephalitis virus replicon particles. Crit Rev Immunol 1999, 19:303-329.

30. Davis NL, Caley IJ, Brown KW, Betts MR, Irlbeck DM, McGrath KM, Connell MJ, Montefiori DC, Frelinger JA, Swanstrom R, et al.: Vaccination of macaques against pathogenic simian immunodeficiency virus with Venezuelan equine encephalitis virus replicon particles [published erratum $J$ Virol 74:3430]. J Virol 2000, 74:371-378

31. Cassetti MC, McElhiney SP, Shahabi V, Pullen JK, Le Poole IC, Eiben GL, Smith LR, Kast WM: Antitumor efficacy of Venezuelan equine encephalitis virus replicon particles encoding mutated HPV16 E6 and E7 genes. Vaccine 2004, 22:520-527.

32. Cheng WF, Hung CF, Hsu KF, Chai CY, He L, Polo JM, Slater LA, Ling $\mathrm{M}, \mathrm{Wu}$ TC: Cancer immunotherapy using Sindbis virus replicon particles encoding a VP22-antigen fusion. Hum Gene Ther 2002, 13:553-568

33. Geisbert TW, Pushko P, Anderson K, Smith J, Davis KJ, Jahrling $\mathrm{PB}$ : Evaluation in nonhuman primates of vaccines against Ebola virus. Emerg Infect Dis 2002, 8:503-507.

34. Lee JS, Dyas BK, Nystrom SS, Lind CM, Smith JF, Ulrich RG: Immune protection against staphylococcal enterotoxininduced toxic shock by vaccination with a Venezuelan equine encephalitis virus replicon. $J$ Infect Dis 2002, 185:1192-1196.

35. Balasuriya UB, Heidner HW, Davis NL, Wagner HM, Hullinger PJ, Hedges JF, Williams JC, Johnston RE, David WW, Liu IK, James MN: Alphavirus replicon particles expressing the two major envelope proteins of equine arteritis virus induce high level protection against challenge with virulent virus in vaccinated horses. Vaccine 2002, 20:1609-1617.

36. Harrington PR Yount $B$, Johnston RE, Davis $N$, Moe $C$, Baric RS: Systemic, mucosal, and heterotypic immune induction in mice inoculated with Venezuelan equine encephalitis replicons expressing Norwalk virus-like particles. J Virol 2002, 76:730-742.
37. Wilson JA, Hart MK: Protection from Ebola virus mediated by cytotoxic $T$ lymphocytes specific for the viral nucleoprotein. $J$ Virol 2001, 75:2660-2664

38. Schultz-Cherry S, Dybing JK, Davis NL, Williamson C, Suarez DL, Johnston R, Perdue ML: Influenza virus (A/HK/156/97) hemagglutinin expressed by an alphavirus replicon system protects chickens against lethal infection with Hong Kong-origin H5N1 viruses. Virology 2000, 278:55-59.

39. Pushko P, Bray M, Ludwig GV, Parker M, Schmaljohn A, Sanchez A, Jahrling PB, Smith JF: Recombinant RNA replicons derived from attenuated Venezuelan equine encephalitis virus protect guinea pigs and mice from Ebola hemorrhagic fever virus. Vaccine 2000, 19:142-153.

40. MacDonald GH, Johnston RE: Role of dendritic cell targeting in Venezuelan equine encephalitis virus pathogenesis. J Virol 2000, 74:914-922.

41. Muller WJ, Sinn E, Pattengale PK, Wallace R, Leder P: Singlestep induction of mammary adenocarcinoma in transgenic mice bearing the activated c-neu oncogene. Cell 1988, 54:105-115.

42. Popesko P, Rajtova V, Horak J: Colour Atlas of Anatomy of Small Laboratory Animals London: Bailliere Tindall; 2003.

43. Ikuta $Y$, Okugawa T, Furugen R, Nagata $Y$, Takahashi $Y$, Wang $L$, Ikeda $\mathrm{H}$, Watanabe $\mathrm{M}$, Imai S, Shiku H: A HER2/neu-derived peptide, a $\mathrm{K}(\mathrm{d})$-restricted murine tumor rejection antigen, induces HER2-specific HLA-A2402-restricted CD8 ${ }^{+}$cytotoxic T lymphocytes. Int J Cancer 2000, 87:553-558.

44. Kreuwel HT, Biggs JA, Pilip IM, Pamer EG, Lo D, Sherman LA: Defective $\mathrm{CDB}^{+} \mathrm{T}$ cell peripheral tolerance in nonobese diabetic mice. J Immuno/ 2001, 167:1112-1117.

45. Andrechek ER, Laing MA, Girgis-Gabardo AA, Siegel PM, Cardiff RD, Muller WJ: Gene expression profiling of neu-induced mammary tumors from transgenic mice reveals genetic and morphological similarities to ErbB2-expressing human breast cancers. Cancer Res 2003, 63:4920-4926.

46. Tang DC, DeVit M, Johnston SA: Genetic immunization is a simple method for eliciting an immune response. Nature 1992 356:152-154.

47. Ulmer JB, Donnelly JJ, Parker SE, Rhodes GH, Felgner PL, Dwarki VJ, Gromkowski SH, Deck RR, DeWitt CM, Friedman A: Heterologous protection against influenza by injection of DNA encoding a viral protein. Science 1993, 259:1745-1749.

48. Schlesinger S: Alphavirus vectors: development and potential therapeutic applications. Expert Opin Biol Ther 2001, 1:177-191.

49. Pilon SA, Piechocki MP, Wei WZ: Vaccination with cytoplasmic ErbB-2 DNA protects mice from mammary tumor growth without anti-ErbB-2 antibody. J Immunol 2001, 167:3201-3206.

50. Lindencrona JA, Preiss S, Kammertoens T, Schuler T, Piechocki M, Wei WZ, Seliger B, Blankenstein T, Kiessling R: CD4+ T cellmediated HER-2/neu-specific tumor rejection in the absence of B cells. Int J Cancer 2004, 109:259-264.

51. Wolpoe ME, Lutz ER, Ercolini AM, Murata S, Ivie SE, Garrett ES Emens LA, Jaffee EM, Reilly RT: HER-2/neu-specific monoclonal antibodies collaborate with HER-2/neu-targeted granulocyte macrophage colony-stimulating factor secreting whole cell vaccination to augment $\mathrm{CD8}^{+} \mathrm{T}$ cell effector function and tumor-free survival in Her-2/neu-transgenic mice. J Immunol 2003, 171:2161-2169. 